Environment Conservation Journal 15(1 \&2), 55-60, 2014

ISSN 0972-3099 (Print) 2278-5124 (Online)

Abstracted and Indexed

\title{
Effect of rhizomes of Curculigo orchioides on Thioacetamide induced hepatotoxicity
}

\author{
Somesh Thapliyal ${ }^{1} \bowtie$, Vijay Juyal ${ }^{2}$ and Anil Bhandari ${ }^{3}$
}

Received: 02.01.2014

Accepted: 15.04.2014

\begin{abstract}
The hepatoprotective activity of methanolic rhizome extract of Curculigo orchioides (MECO) were evaluated against Thioacetamide-induced hepatic damage in rats. The MECO at dose of 100,200 and $400 \mathrm{mg} / \mathrm{kg}$ were administered orally once daily for 21 days and simultaneously administered TAA $100 \mathrm{mg} / \mathrm{kg} \mathrm{b.w.} \mathrm{s.c.} 1 \mathrm{~h}$ after the respective assigned treatments every $72 \mathrm{~h}$. Serum enzymatic levels of serum glutamate oxaloacetate transaminase (AST), serum glutamate pyruvate transaminase (ALT), serum alkaline phosphatase (ALP) and total bilirubin were estimated along with estimation of superoxide dismutase (SOD) and malondialdehyde (MDA) levels in liver tissues.
\end{abstract}

Keywords: Amaryllidaceae, Curculigo orchioides, hepatoprotective, silymarin, thioacetamide

\section{Introduction}

Curculigo orchioides belonging to family Amaryllidaceae or Hypoxidaceae; is an ayurvedic traditional medicinal plant known as Taalmuuli, Taalpatri, Krishna Mushali, Bhuumitaala in ayurveda (Anonymous; Ayurvedic Pharmacopoeia., 2004) The plant is found in Sub-tropical Himalayas from Kumaun eastwards; Western Ghats from Konkan Southwards. The root plant is as nervine, adaptogenic, sedative, anticonvulsive, androgenic, anti-inflammatory and diuretic. Used in Jaundice, urinary disorders, skin diseases and asthma (Khare., 2007). Biologically immunostimulatory effect (Lakshmi et al., 2003; Bafna \& Mishra., 2006), anti-osteoporotic activity (Jiao et al., 2009), neuroprotective effect (Tian et al., 2012), antihistaminic potential (Venkatesh et al., 2009), estrogenic activity (Vijayanarayana et al., 2007) of Curculigo orchioides have been reported. The plant also modifies the activity and protein expression of CYP3A in normal and kidney yang deficiency model rats (Wang et al., 2012). Curculigo orchioides, a traditional Chinese medicinal plant, prevents bone loss in ovariectomized rats (Cao et al., 2008). The rhizomes of Curculigo orchioides

Author's Address

${ }^{1}$ Department of Pharmaceutical Sciences HNB Garhwal (A Central) University, Srinagar Garhwal Uttarakhnd, India.

${ }^{2}$ Department of Pharmaceutical Sciences, Kumaun University, Bhimtaal, Uttarakhand, India.

${ }^{3}$ Department of Pharmaceutical Sciences, Jodhpur National University, Jodhpur, Rajasthan, India.

Email: somesh.thapliyal@ gmail.com

Copyright by ASEA

All rights of reproduction in any form reserved have been traditionally used as aphrodisiac (Chauhan et al., 2007). The rhizomes contains phenolic glycosides like curculigoside E, orchioside (Dall'Acqua et al., 2009), orchiosides A \& B ( Gupta et al., 2005), curculigoside A, curculigoside B, curculigine A, curculigine D (Jiao et al., 2009). Isolation of phytoconstituents like triterpene ketone (Jiao et al 2013), benzyl benzoate glucoside (Valls et al., 2006) have been performed. A peptide, Curculin C, containing 114 amino acids, has been isolated from the fruit. In Indian medicine, powdered rhizomes with milk are taken as a restorative tonic, also for sexual debility. EtOH $(50 \%)$ of the plant exhibited hypoglycaemic property (Asif, 2012). Liver is the largest organ in vertebrate body, is the major site of intense metabolic activities. The major functions of the liver are carbohydrate, protein, fat metabolism, detoxification, storage of vitamins, secretion of bile and blood clotting factors like prothrombin and fibrinogen. Liver injury caused by toxic chemicals and certain drugs has been recognised as a toxicological problem. According to WHO about 18,000 people die every year due to hepatic diseases. The common ailments of liver are cirrhosis, cholestasis, hepatitis, portal hypertension, hepatic encephalopathy, hepatic failure and certain tumours like hepatoma. Excess consumption of certain toxic chemicals such as antibiotics, chemotherapeutics, peroxidised oils, acetaminophen, aflatoxins, carbon tetrachloride, chlorinated 
hydrocarbons, alcohol etc., leads to infections and autoimmune disorders (Wolf, 1999).

Thioacetamide is originally used as a fungicide and later on found to be a potent hepatotoxic agent. It is bioactivated by CYP450 and/or Flavin-Containing Monooxygenase (FMO) systems to sulfine sulfoxide and sulfene (sulfone) metabolites, which cause centrilobular necrosis. Thioacetamide sulfoxide is a relatively stable intermediate of thioacetamide and is obligatory for the hepatotoxic effects. A single large dose $100 \mathrm{mg} / \mathrm{kg}$ causes degenerative changes in 6-8 $\mathrm{h}$ followed by centrizonal necrosis in $24 \mathrm{~h}$ (Low et al., 2004).

Herbal drugs play a crucial role in the management of various liver disorders most of which speed up the natural healing processes of the liver. The present study was, therefore, aimed to assess the hepatoprotective and anti oxidant activity of methanolic extract of rhizomes of Curculigo orchioides.

\section{Materials and methods}

\section{Collection of Plant Material}

Rhizomes of Curculigo Orchiodes were collected from in around Dehradun and the sample was authenticated by Dr. R.L.Painuli, Department of Botany, HNB Garhwal University, Srinagar Garhwal Uttarakhand (Specimen voucher no. GUH13123).

\section{Preparation of plant extract}

The sample washed, freed from soil and all dried in shade. Coarsely powdered rhizomes were successively extracted in the Soxhlet apparatus using petroleum ether, chloroform, ethyl acetate, methanol and water as solvent for the complete extraction of the phytoconstituents. All extracts were dried in rotary evaporator at $45^{\circ} \mathrm{C}$ and the dried extracts were stored in vacuum desiccators containing anhydrous silica gel.

\section{Test Animals:}

Wistar rats (180-240 g) of either sex procured from the central animal house were used for the study. The animals were housed in large, clean polypropylene cages in a temperature- Controlled room with relative humidity (44-55\%) under $12 \mathrm{~h}$. light and dark cycles. All the animals were acclimatized to laboratory environment for a week prior to experiments. Animals were provided with a standard rodent pellet diet and clean drinking water ad libitum. The care and use of laboratory animals were strictly in accordance with the guidelines prescribed by the Institutional Animal Ethical Committee constituted under the guidelines of Committee (1205/C/08/CPCSEA) for the Purpose of Control and Supervision of Experiments on Animals (CPCSEA), India.

\section{Acute toxicity studies}

An acute oral toxicity study was performed according to the OECD guidelines for the testing of chemicals, Test No. 423 (OECD, 2001; Acute oral toxicity-Acute toxic class method). Wistar rats $(\mathrm{n}=$ 3 ) of either sex were selected by a random sampling technique for the acute toxicity study. The animals were fasted overnight prior to the experiment and maintained under standard laboratory conditions. Each extract was administrated orally in increasing dose up to $2000 \mathrm{mg} / \mathrm{kg}$.

\section{In vivo hepatoprotective activity: Experimental design:}

A total of 36 albino wistar rats between 180-240gm were divided into six groups, each group consisting of six animals. Group I served as normal control and received the vehicle viz. normal saline (2 $\mathrm{mL} / \mathrm{kg}$ p.o.). Rats in group II received TAA 100 $\mathrm{mg} / \mathrm{kg}$ bw s.c., every $72 \mathrm{~h}$. for 21 days. Group III received silymarin $100 \mathrm{mg} / \mathrm{kg}$ p.o. for 21 days and simultaneously administered TAA $100 \mathrm{mg} / \mathrm{kg}$ b.w. s.c. $1 \mathrm{hr}$ after the respective assigned treatments every $72 \mathrm{~h}$. Rats of group IV, V and VI were administered MECO at 100, 200 and $400 \mathrm{mg} / \mathrm{kg}$ body weight p.o. respectively for 21 days and simultaneously administered TAA $100 \mathrm{mg} / \mathrm{kg}$ bw s.c. $1 \mathrm{~h}$ after the respective assigned treatment every $72 \mathrm{~h}$. At the end of experimental period, all the animals were sacrificed by cervical dislocation. Blood was collected from the retro-orbital sinus plexus under mild ether anaesthesia, just before sacrifice and allowed to clot. Serum was separated by centrifugation and analyzed for various biochemical parameters.

Measurement of serum biochemical parameters: The parameters of serum aspartate transaminase (AST), alanine transaminase (ALT), alkaline phosphatase (ALP) and total bilirubin were determined using the Hitachi 912 clinical chemistry automatic analyzer (Roche Diagnostic Gmbh, Mannheim, Germany). 
Assessment of lipid peroxidation and superoxide dismutase (SOD):

In chilled normal saline excised livers were perfuse to remove all the blood cells. Then they were cut down into small pieces, placed in $0.1 \mathrm{M}$ phosphate buffer ( $\mathrm{pH}$ 7.4), and homogenized using remi homogenizer to obtain $20 \%$ homogenate. The homogenate thus obtained was centrifuged at 3000 rpm for $15 \mathrm{~min}$ and the supernatant was collected in an Eppendorf tube. This supernatant was again centrifuged at $12,000 \mathrm{rpm}$ for $30 \mathrm{~min}$. The final supernatant was used for the determination of malonaldehyde (MDA) as a lipid peroxidation marker (Nourooz-Zadeh et al., 1995). Superoxide dismutase (SOD) was also assayed by the method described previously (Misra and Fridovich, 1972).

Histopathology:

The liver tissue was dissected out and fixed in $10 \%$ formalin solution. It was then dehydrated in etanol (50-100\%), cleared in xylene and embedded in paraffin wax. Afterwards thick sections $(5-6 \mathrm{~mm})$ were made and then stained with hematoxylin and eosin dye for photomicroscopic observation (Hirayama et al., 1979, Ala-Kokko et al., 1987).

\section{Statistical analysis}

The data were expressed as mean \pm SD. Statistical differences at $p<0.001$ between the groups were analyzed by one-way ANOVA followed by Turkey as post hoc using GraphPad Instat software package.

\section{Results and Discussion Acute toxicity studies}

All the extracts of Curculigo orchioides rhizomes did not cause any mortality upto 2000 $\mathrm{mg} / \mathrm{kg}$ dose level. Hence $1 / 20^{\text {th }}, 1 / 10^{\text {th }}$ and $1 / 5^{\text {th }}$ of the maximum dose (i.e., 100, 200 and $400 \mathrm{mg} / \mathrm{kg}$, p.o.) were selected for the present study.

\section{In vivo hepatoprotective activity:}

The hepatoprotective effects of MECO on serum biochemical parameters in thioacetamideintoxicated rats are shown in Table 1. Rats treated with thioacetamide (Group II) showed a significant increase in serum AST, ALT, ALP and total bilirubin levels compared to control animals (Group I). Pre-treatment with MECO at 100, 200 and 400 $\mathrm{mg} / \mathrm{kg}$ doses (Groups IV, V and VI) showed significant hepatoprotection in terms of serum AST,
ALT, ALP and total bilirubin levels compared to the toxic control group (Group II). At $400 \mathrm{mg} / \mathrm{kg}$ dose, MECO revealed significant hepatoprotection. Pre-treatment with the standard hepatoprotective agent-Silymarin (Groups III) also decreased all measured serum biochemical activities towards normalness.

\section{Effect of MECO on MDA and SOD levels:}

Lipid peroxidation was increased in the toxic control group, as revealed by elevated MDA levels, when compared with the normal control group. Pretreatment with MECO at 100, 200 and $400 \mathrm{mg} / \mathrm{kg}$ decreased the MDA levels, which were different to those of rats receiving the standard drug Silymarin. A level of antioxidant enzyme, SOD was increased in MECO treated groups. The extract at the dose of $400 \mathrm{mg} / \mathrm{kg}$ demonstrated maximum hepatoprotection as shown in table 1 .

\section{Histopathology:}

Histopatholigical observations revealed that the normal architecture of liver was completely lost in rats treated with thiacetamide with the presence of inflammation of cells, necrosis and blooming degeneration of hepatocytes (Figure 1). Prophylactic treatment with MECO at dose $100 \mathrm{mg} / \mathrm{kg}$ showed severe inflammation and necrosis. At a dose 200mg/kg MECO showed less inflammation and mild to moderate necrosis compared to toxic control group. Liver section of rats treated with MECO at $400 \mathrm{mg} / \mathrm{kg}$ bear witness more or less normal lobular pattern with short septa of connective tissue and a mild degree of fatty change, and necrosis comparable to control and silymarin treated group.

The present study demonstrates the hepatoprotective and antioxidant effects of MECO against Thioacetamide-induced liver injury in rats. The liver mainly detoxifies toxic chemicals and drugs and becomes the main target organ for all possible toxic xenobiotics. Thioacetamide administration is an established technique for generating rat models of liver fibrosis and cirrhosis. Oxidative stress is believed to be involved as TAAinduced liver fibrosis is initiated by thioacetamide S-oxide, which is derived from the biotransformation of Thioacetamide by the microsomal flavine-adenine dinucleotide (FAD)containing monooxygense (FMO) and cytochrome P450 systems (Low et al., 2004). 
Figure 1: Representative photomicrograph of liver sections from Group I to Group VI
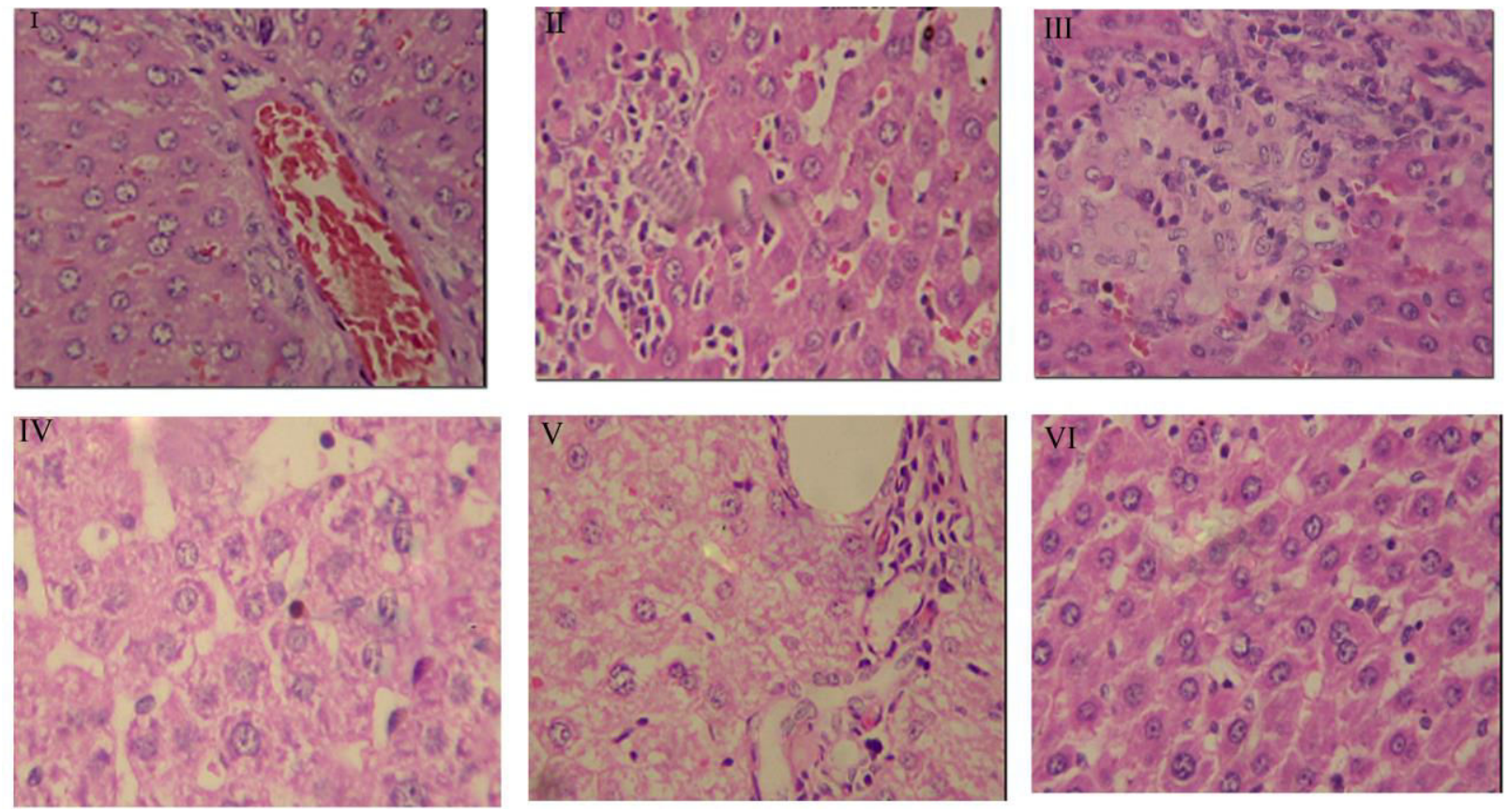

Table: 1 MECO on serum biochemical parameters in Thioacetamide-intoxicated rats

\begin{tabular}{|c|c|c|c|c|c|c|c|}
\hline Group & Treatment & $\begin{array}{l}\text { AST (SGOT) } \\
(\text { IU/L) }\end{array}$ & $\begin{array}{l}\text { ALT (SGPT) } \\
(\text { IU/L) }\end{array}$ & $\begin{array}{l}\text { ALP } \\
(\mathrm{IU} / \mathrm{L})\end{array}$ & $\begin{array}{l}\text { Serum } \\
\text { Billirubin } \\
(\mathrm{mg} / \mathrm{dl})\end{array}$ & MDA & SOD \\
\hline Group I & Control & $150 \pm 2.8^{\mathrm{a}}$ & $95 \pm 3.7^{\mathrm{a}}$ & $85 \pm 3.9^{\mathrm{a}}$ & $0.47 \pm 0.09^{\mathrm{a}}$ & $86 \pm 0.21^{\mathrm{a}}$ & $7.5 \pm 0.15^{\mathrm{a}}$ \\
\hline Group II & $\begin{array}{l}\text { Thioacetamide } \\
(100 \mathrm{mg} / \mathrm{kg} \mathrm{s.c.})\end{array}$ & $384 \pm 18.5$ & $261 \pm 8.4$ & $198 \pm 6.3$ & $0.88 \pm 0.07$ & $127 \pm 2.4$ & $3.6 \pm 0.18$ \\
\hline Group III & $\begin{array}{l}\text { Silymarin } 100 \mathrm{mg} / \mathrm{kg}+ \\
\text { Thioacetamide } \\
(100 \mathrm{mg} / \mathrm{kg} \text { s.c. })\end{array}$ & $190 \pm 11.4^{* * *}$ & $112 \pm 1.5^{* * *}$ & $99 \pm 2.4^{* * *}$ & $0.54 \pm 0.06^{* * *}$ & $97 \pm 2.2^{* * *}$ & $7.1 \pm 0.14^{* * *}$ \\
\hline Group IV & $\begin{array}{l}\text { MECO } 100 \mathrm{mg} / \mathrm{kg}+ \\
\text { Thioacetamide } \\
\text { (100 mg/kg s.c.) }\end{array}$ & $370 \pm 2.6$ & $246 \pm 3.8^{* * * *}$ & $198 \pm 5.3^{* *}$ & $0.82 \pm 0.23^{* * *}$ & $122 \pm 2.5^{* * *}$ & $3.7 \pm 0.39^{* * *}$ \\
\hline Group V & $\begin{array}{l}\text { MECO } 200 \mathrm{mg} / \mathrm{kg}+ \\
\text { Thioacetamide } \\
(100 \mathrm{mg} / \mathrm{kg} \text { s.c. })\end{array}$ & $228 \pm 5.4^{* * * *}$ & $184 \pm 2.4^{* * * *}$ & $160 \pm 4.7^{* *}$ & $0.64 \pm 0.07^{* * * *}$ & $114 \pm 0.73^{* *}$ & $4.5 \pm 0.32^{* * *}$ \\
\hline Group VI & $\begin{array}{l}\text { MECO } 400 \mathrm{mg} / \mathrm{kg}+ \\
\text { Thioacetamide } \\
(100 \mathrm{mg} / \mathrm{kg} \text { s.c. })\end{array}$ & $193 \pm 3.2^{* * * *}$ & $116 \pm 5.8^{* * * *}$ & $100 \pm 8.1^{* *}$ & $0.53 \pm 0.16^{* * *}$ & $97 \pm 0.72^{* * *}$ & $7.1 \pm 0.49^{* * *}$ \\
\hline
\end{tabular}

MECO: Methanolic extract of Curculigo orchioides. Data are expressed as mean \pm SD $(n=6)$.

One-way ANOVA Tukey post hoc: $* * * p<0.001$ 
Thioacetamide was chosen for this experiment because it consistently produces liver cirrhosis in rats with histological appearance that is more akin to human cirrhosis. Thioacetamide is a thionosulfur containing compound that is necrogenic and carcinogenic. It is commonly used for inducing fulminant hepatic failure and liver cirrhosis in animal models. During the biotransformation of Thioacetamide, both flavin-containing monooxygenase (FMO) and cytochrome P450 reduce dioxygen to superoxide anion, which is then catalyzed to form hydrogen peroxide $\left(\mathrm{H}_{2} \mathrm{O}_{2}\right)$. Therefore, biotransformation of Thioacetamide precedes oxidative damage associated liver injury. This had been implicated earlier by the presence of glutathione depletion, an increase in malondialdehyde (MDA) and the disappearance of tetraploid hepatocytes in liver cells following Thioacetamide administration.

Lipid peroxidation is an important parameter of oxidative stress along with other free radical damage occurred in the biochemical cascade. Therefore, antioxidant efficacy is regarded as one of the most important parameter indicative of the possible mechanism of hepatoprotection. AST, ALT and ALP are the serum hepatobillary enzymes present normally in the liver in high concentrations. Upon necrosis or hepatic damage these enzymes will be leaked into the circulation; raising serum concentration of these enzymes (Drotman and Lawhan, 1978). Elevated serum AST, ALT and ALP levels in Thiocetamide treated animals indicated cellular breakage and loss of functional integrity of cell membranes in liver (Wolf, 1999, Drotman and Lawhan, 1978).

In the present study, increased MDA levels in liver indicated increased lipid peroxidation induced by Thioacetamide (Group II animals). This enhanced lipid peroxidation finally triggered hepatic tissue damage. Reduced estimation of SOD in Thioacetamide treated animals also suggested failure of antioxidant defense mechanism to block peroxidation damage. In view of this, the increased serum level of AST, ALT and ALP enzymes in Thioacetamide treated animals (Group II) confirmed hepatic damage. As a breakdown product of haeme in red blood cells, bilirubin is regarded as a clinical and pathophysiological indicator of necrosis of liver tissues. Pretreatment with MECO in different animal groups (Group IV/V/VI) resulted a significant decrease in serum AST, ALT, ALP and total bilirubin levels as compared to Thioacetamide treated group (Group II). Prophylactic use of the extract resulted in an inhibition of the degree of hepatic necrosis and concomitantly decreased the leakage of intracellular enzymes by stabilizing hepatic cellular membranes. Inhibition of lipid peroxidation to a significant degree is also a predominant mechanism of hepatoprotection as suggested by the significant decrease in MDA levels. Increase in the SOD level was also suggestive of repairment of antioxidant defense system, which plays an important role in hepatoprotection. Based upon the results of present study, it can be concluded that the methanol extract of Curculigo orchioides has proven itself as a significant hepatoprotective as well as a considerable antioxidant.

\section{Conclusion}

The present study clearly demonstrated the in vivo' hepatoprotective activity of the methanol extract of rhizomes of Curculigo orchioides along with its antioxidant mechanism of action.

\section{References}

Ala-Kokko, L., Stenback, F. \& Ryhanen, L. 1987. Preventive effect of malotilate on carbon tetrachloride induced liver damage and collagen accumulation in the rat.Biochemical journal, 246: 503-509.

Anonymous. Ayurvedic pharmacopoeia of India 2004. In: Ayush, editor. $1^{\text {st }}$ ed. New Delhi: Ayush.

Asif, M. 2012. A review on phytochemical and ethnopharmacological activities of curculigo orchioides. Mahidol university journal of pharmaceutical sciences, 39(3.4): 1-10.

Bafna, A. R., Mishra, S. H. 2006. Immuno stimulatory effect of methanol extract of Curculigo orchioides on immuno suppressed mice. Journal of Ethno pharmacology, 104: $1-4$.

Cao, D. P., Zheng, Y. N., Qin, L. P., Han, T., Zhang, H., Rahman, K. and Zhang, Q. Y. 2008. Curculigo orchioides, a traditional Chinese medicinal plant, prevents bone loss in ovariectomized rats. Maturitas, 59: 373-380.

Chauhan, N. S., Rao, C. V. and Dixit, V. K. 2007. Effect of Curculigo orchioides rhizomes on sexual behaviour of male rats. Fitoterapia, 78: 530-534. 
Dall'acqua, S., Shrestha, B. B., Comai, S., Innocenti, G., Gewali, M. B. and Jha, P. K. 2009. Two phenolic glycosides from Curculigo orchioides Gaertn Fitoterapia, 80: 279-282.

Drotman, R. and Lawhan, G. 1978. Serum enzymes are indications of chemical induced liver damage. Drug Chem Toxicol, 1: 163-171.

Gupta, M., Achari, B. and Pal, B. C. 2005. Glucosides from Curculigo orchioides Phytochemistry. 66: 659-663.

Hirayama, C., Morotami, I. and Hiroshige, K. 1979. Quantitative and metabolic changes of hepatic collagens in rats after carbon tetrachloride poisoning. Biochemical journal, 118: 229-302.

Jiao, L., Cao, D.-P., Qin, L.-P., Han, T., Zhang, Q.-Y., Zhu, Z. and Yan, F. 2009. Antiosteoporotic activity of phenolic compounds from Curculigo orchioides, Phytomedicine, 16: $874-881$.

Jiao, W., Chen, X., Wang, H., Lu, R. and Shao, H. 2013. A new hepatotoxic triterpenoid ketone from Curculigo orchioides. Fitoterapia, 84: 1-5.

Khare CP., 2007. Indian Medicinal Plants: An Illustrated Dictionary: Springer.

Lakshmi, V., Pandey, K., Puri, A., Saxena, R. P. and Saxena, K. C. 2003. Immuno stimulant principles from Curculigo orchioides. Journal of Ethnopharmacology, 89: 181-184.

Low,Teck yew., Maxey and Chung C.M. 2004. A proteomic analysis of thioacetamide induced hapatotoxicity and cirrhosis in rat livers. Proteomics, 4: 3960-3974.

Misra, H. P. and Fridovich, I. 1972. Role of superoxide anion in the autoxidation of epinephrine and a simple assay for superoxide dismutase. Journal of Biological Chemistry, 247: 3170 .

Nourooz-Zadeh, J., Tajaddini-Sarmadi, J., Mccarthy, S., Betteridge, D. J. and Wolff, S. P. 1995. Elevated levels of authentic plasma hydroperoxides in NIDDM. Diabetes, 44: 1054-1058.

Tian, Z., Yu, W., Liu, H.-B., Zhang, N., Li, X.-B., Zhao, M.-G. and Liu, S.B. 2012. Neuroprotective effects of curculigoside against NMDA-induced neuronal excitoxicity in vitro. Food and Chemical Toxicology, 50: 4010-4015.

Valls, J., Richard, T., Larronde, F., Leblais, V., Muller, B., Delaunay, J.-C., Monti, J.-P., Ramawat, K. G. and Mérillon, J.-M. 2006. Two new benzylbenzoate glucosides from Curculigo orchioides. Fitoterapia, 77: 416-419.

Venkatesh, P., Mukherjee, P. K., N, S. K., Nema, N. K., Bandyopadhyay, A., Fukui, H. and Mizuguchi, H. 2009. Mast cell stabilization and antihistaminic potentials of Curculigo orchioides rhizomes. Journal of Ethnopharmacology, 126: 434-436.

Vijayanarayana, K., Rodrigues, R. S., Chandrashekhar, K. S. and Subrahmanyam, E. V. S. 2007. Evaluation of estrogenic activity of alcoholic extract of rhizomes of Curculigo orchioides. Journal of Ethnopharmacology, 114: $241-245$

Wang, C.-M., Xu, S.-Y., Lai, S., Geng, D., Huang, J.-M. and Huo, X.Y. 2012. Curculigo orchioides (Xian Mao) modifies the activity and protein expression of CYP3A in normal and Kidney-Yang Deficiency model rats. Journal of Ethnopharmacology, 144: 33-38.

Wolf, P. L. 1999. Biochemical diagnosis of liver diseases. Indian Journal of Clinical Biochemistry, 14: 59-90. 